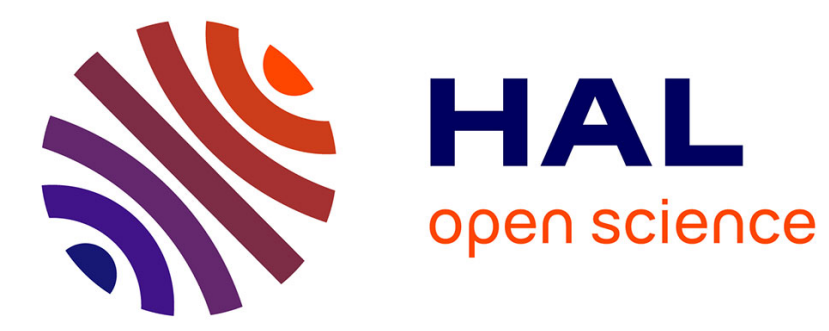

\title{
UNE MÉTHODE DE TITRAGE DU "BACTERIUM COLI " DANS LE LAIT, LE BABEURRE, LE FROMAGE
}

\author{
M. Lerner
}

\section{- To cite this version:}

M. Lerner. UNE MÉTHODE DE TITRAGE DU " BACTERIUM COLI " DANS LE LAIT, LE BABEURRE, LE FROMAGE. Le Lait, 1935, 15 (148), pp.833-853. hal-00895206

\section{HAL Id: hal-00895206 https://hal.science/hal-00895206}

Submitted on 1 Jan 1935

HAL is a multi-disciplinary open access archive for the deposit and dissemination of scientific research documents, whether they are published or not. The documents may come from teaching and research institutions in France or abroad, or from public or private research centers.
L'archive ouverte pluridisciplinaire HAL, est destinée au dépôt et à la diffusion de documents scientifiques de niveau recherche, publiés ou non, émanant des établissements d'enseignement et de recherche français ou étrangers, des laboratoires publics ou privés. 


\title{
LE LAIT
}

REVUE GENERALE DES QUESTIONS LAITIÉRES

SOMMAIRE

\section{Mémoires originaux :}

M. Lerner. - Une méthode de titrage du Bacterium Coli dans le lait, le babeurre, le fromage . . . .

Groн. - L'influence de la durée des intervalles des traites sur la sécrétion du lait et sa teneur en matière grasse .......

J. Brisou. - Analyse baetériologique des beurres dans la région de Brest. Biologie du bacille typhique dans le beurre

\section{3}

Revue :

G, GÉnin. - Les agents de nettoyage employés dans l'industrie laitière

\section{Bibliographie analytique :}

10 Les livres . . . . . . .

$2^{\circ}$ Journaux, Revues, Sociétés savantes "

\section{Bulletin bibliographique :}

10 Journaux, Revues, Sociétés savantes..............

$\mathrm{X}^{\mathrm{e}}$ Congrès mondial de laiterie (Rome-Milan, 30 avril-6 mai 1934). $6^{e} \mathrm{sec}$ tion:

L. Panisset. - Les infections de la mamelle: com. ment elles influent sur la valeur hygiénique du lait alimentaire et sur les dérivés du lait . . . . . . .

M. Rinjard. - Les Brucelloseset le lait.

\section{Documents et informations :}

N. R. Göransson. - Le IVe Congrès international tech. nique et chimique des industries agricoles . . .

Les belles installations en laiterie. - VII. L' "Industrie

- laitière „ de Prague . . . .

Loi du 2 juillet 1935 tendant à l'organisation et à l'assainissement des marchés du lait et des produits résineux... . . . . .

Arrêté du 5 juillet 1935 nommant des membres du comité central du lait ...

Décret du 25 juillet 1935 relatif à l'exportation des beurres

\section{MÉMOIRES ORIGINAUX (1)}

\section{UNE MÉTHODE DE TITRAGE DU "BACTERIUM COLI " DANS LE LAIT, LE BABEURRE, LE FROMAGE (2)}

\author{
par M. LERNER
}

du Service d'Inspection des Denrées Aliməntaires, Amsterdam.

Dans un laboratoire exerçant le contrôle du commerce du lait une méthode expéditive de détermination de la présence éventuelle

(1) Reproduction interdite sans indication de source.

(2) La Revue Le Lait adresse à son dévoué collaborateur Monsieur Göransson, ses plus vifs remerciements pour cette traduction délicate et si fidèle. 
du Bacterium Coli dans le lait pasteurisé et dans $1 / 10^{\mathrm{e}}$ de eentimètre cube de lait-modèle ( 1 ) est nécessaire, tandis que la détermination rapide du nombre de ces organismes dans le lait de marché ordinaire serait un moyen de contrôle des soins apportés à la produetion de ce lait. La méthode Ringeling, une méthode d'aceumulation, doit être suivie de la préparation de cultures sur plaques et de la détermination des caractéristiques des colonies qui s'y développent ; ce procédé d'identification des organismes du groupe Coli, appliqué à un grand nombre d'échantillons, demande de 3 à 4 jours, et exige beavcoup de matériel et beaucoup de travail. On cherche done depuis longtemps une méthode assez simple pour être appliquée sur une grande échelle et qui fournisse rapidement des résultats convenables.

Au cours des dernières années, certains laboratoires appliquent la méthode dite Pegallac, et j'ai voulu contrôler l'exactitude de cette méthode. Avant de communiquer les résultats de mes recherches, je crois devoir affirmer, que, d'aceord avec les avis émis par P. C. FLU (Leerboek der parasitaire zieleten), par E. GORTER et W. C. DE GrAAFF (Klinische diagnostiek) et par A. BEYTHIEN (Handbuch der Nahrungsmitteluntersuchung, part. III), je considère seulement comme Bacterium Coli un organisme qui coagule le lait, forme de l'indol, rend fluorescent le rouge neutre et produit du gaz dans des solutions aqueuses de glucose-peptone et de lactose-peptone.

Pour la méthode Pegallac, on utilise une solution à $1 \%$ de peptone, $1 / 2 \%$ de lactose et $3 \%$ de bile de boeuf stérilisée par le maintien pendant $1 / 4$ d'heure à la température de $100^{\circ} \mathrm{C}$., puis filtrée et additionnée d'une solution de tournesol à $3 \%$. Des éprouvettes contenant $\pm 15 \mathrm{~cm}^{3}$ de cette solution sont stérilisées par le maintien pendant $1 / 2$ heure à la température de $100^{\circ} \mathrm{C}$. On mélange le contenu d'une éprouvette avec $1 \mathrm{~cm}^{3}$ du lait dans lequel on veut déterminer la présence d'organismes du groupe Coli; le mélange, mis dans un tube à fermentation, est conservé à la température de $37^{\circ} \mathrm{C}$, et après \pm 24 heures, on examine si la couleur de la solution est devenue rose ou blanche et s'il y a eu dégagement de gaz. Cette méthode est également employée comme méthode de titrage du Bacterium Coli: lors de dégagement gazeux abondant, on estime que les organismes Coli sont nombreux.

J'ai appliqué à 998 échantillons de lait pasteuricé et à 24 échantillons de lait-modèle la méthode Pegallac et la méthode Ringeling (accumulation par développement dans du bouillon acide). Detoutes les cultures obtenues avec les deux méthodes d'accumulation furent préparées des plaques d'agar d'Endo, et pour tous les échantillons, il fut examiné si les colonies développées présentaient les caractéristiques mentionnées plus haut.

(1) Modelmelk. - Lait cru produit dans des conditons similaires à celles $\in x i g c ́$ ‘s $f \in$ ur la production du "Certified Milk " (lait certifié) aux Etats-Unis et en Angleterre. 
Les résultats obtenus sont donnés au tableau I.

TABLEAU 1.

Coli

Pegallac Ringeling

présent dans

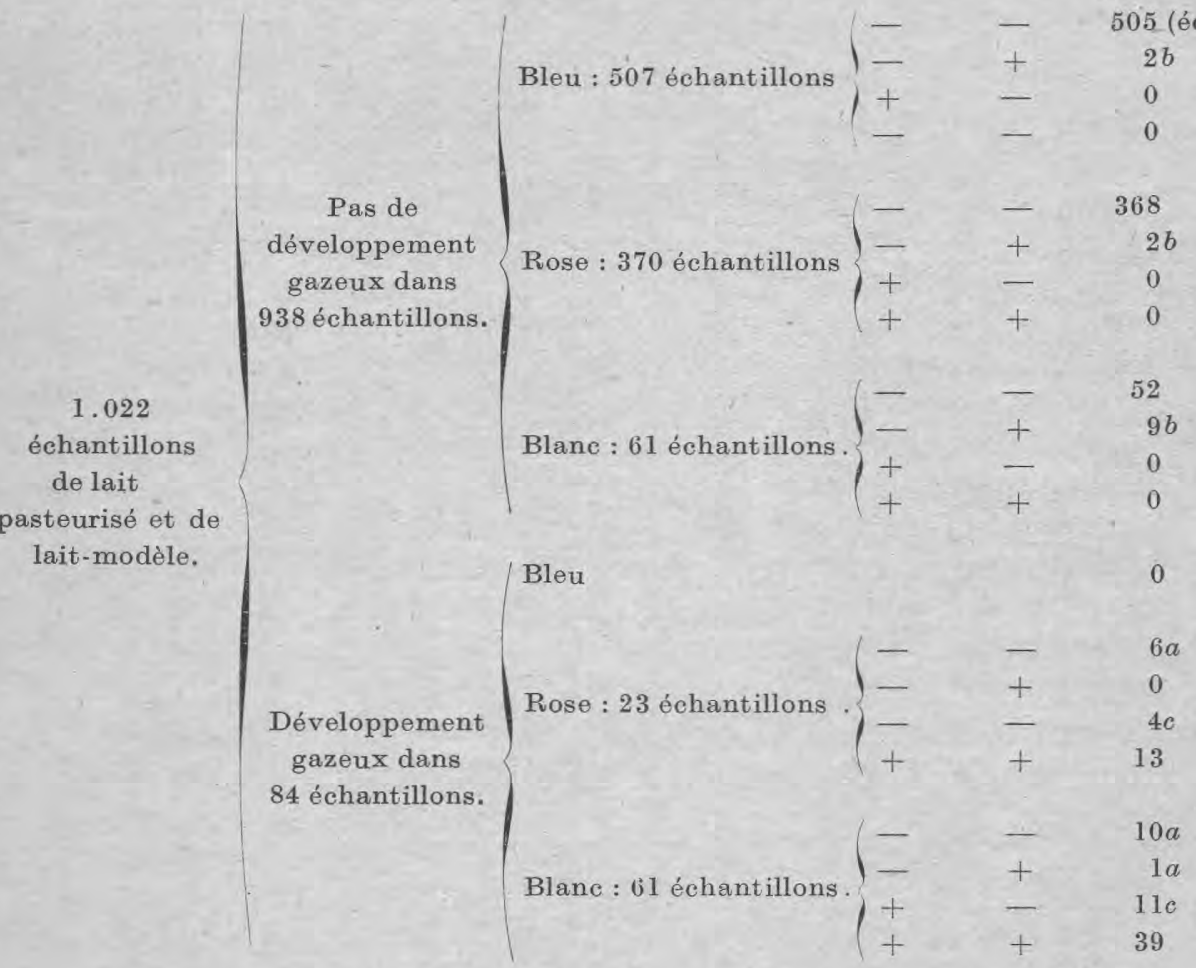

Ces données édifient sur la valeur qu'on doit attacher à la -méthode Pegallac comme indicatrice de la présence ou de l'absence d'organismes du groupe Coli. Des indications erronées se présentent tant dans l'une que dans l'autre direction, c'est-à-dire, parfois le Pegallac indique la présence de Bacterium Coli lorsqu'il est absent (dans 17 eas, marqués a), et parfois le Pegallac n'indique pas le Bacterium Coli lorsqu'il est présent (dans 13 cas, marqués $b$ ), un dégagement de gaz et les colorations blanche et rouge étant considérées comme des résultats positifs Pegallac. D'autre part, cependant, nous avons 15 cas (marqués $c$ ) où la plaque d'agar d'Endo préparée en partant de la culture Pegallac confirma la présence du Bacterium Coli indiquée par la méthode Pegallac, tandis que la méthode Ringeling fournit des résultats négatifs. Parmi les indications erronées fournies par la méthode Pegallac, graves sont celles (17 résultats positifs sur 84) qui indiquent la présence du Bacterium Coli 
lorsqu'il est absent ; elles indiqueraient que la méthode est inexacte en principe ; en fait, il y a dégagement de gaz et coloration blanche ou rouge par d'autres bactéries, qui se trouvent dans le lait et qui ne présentent pas les caractéristiques du groupe Coli, et cela dans $20 \%$, certainement, des laits qui fournissent des résultats positifs par la méthode de Pegallac.

Les autres indications erronées, où le Bacterium Coli ne fut pas indiqué par la méthode Pegallac (13 cas), où il ne fut pas révélé par la méthode Ringeling (15 cas), doivent être considérées comme dues au hasard. Il est évident, que lorsque les organismes Coli sont peu nombreux, et qu'on applique plusieurs fois la même méthode de détermination, que ce soit la méthode Pegallac ou la méthode Ringeling, on constatera de ees différences dans les résultats. Le titrage du Bacterium Coli (dans l'eau), selon MAC ConkeY, est d'ailleurs basé sur les différences existant entre de tels résultats. Dans le lait pasteurisé et dans le lait-modèle, les organismes Coli sont toujours peu nombreux ; donc, on peut toujours s'attendre à des indications erronées de ce genre. Ce qui vient d'être dit est bien démontré par l'expérience suivante. Des dilutions toujours plus grandes d'un même échantillon de lait cru furent examinées par la méthode de Ringeling et par la méthode de Pegallac; pour chacune des dilutions dix épreuves furent faites. Les résultats obtenus sont indiqués au tableau II.

Pour les dilutions moyennes, les épreuves parallèles donnent, tant par la méthode Pegallac que par la méthode de Ringeling, une fois + , une autre fois - ; d'où on est autorisé à conclure, que pour un grand nombre d'échantillons de lait à teneur à peu près égale en organismes Coli, un seul examen, par la méthode Pegallac et par la méthode de Ringeling, aurait donné lieu à des indications erronées,

TABLEAU II.

Développement de gaz en centimètres cubes.

$\begin{array}{llllllllllllll}\text { Dilution } 1: 10 \ldots \ldots & 2 & 21 / 4 & 21 / 2 & 21 / 2 & 21 / 2 & 23 / 4 & 23 / 4 & 3 & 3 & 31 / 2 & 10 & 0 \\ \text { Dilution } 1: 100 \ldots \ldots & 1 & 11 / 4 & 1 \frac{1 / 2}{13 / 4} & 13 / 4 & 13 / 4 & 13 / 4 & 2 & 2 & 21 / 4 & 10 & 0 \\ \text { Dilution } 1: 500 \ldots \ldots & - & - & + & + & 1 & 11 / 4 & 11 / 4 & 11 / 2 & 11 / 2 & 2 & 10 & 0 \\ \text { Dilution } 1: 1.000 \ldots \ldots & - & - & - & + & 1 / 2 & 1 / 2 & 11 / 4 & 11 / 2 & 11 / 2 & 11 / 2 & 10 & 0 \\ \text { Dilution } 1: 5.000 \ldots \ldots & - & - & - & - & - & - & - & 1 / 4 & 1 / 2 & 3 / 4 & 9 & 1 \\ \text { Dilution } 1: 10.000 \ldots & - & - & - & - & - & - & - & - & - & - & 8 & 2 \\ \text { Dilution } 1: 20.000 \ldots & - & - & - & - & - & + & 1 / 4 & 1 / 4 & 1 / 2 & 1 / 2 & 7 & 3 \\ \text { Dilution } 1: 50.000 \ldots & - & - & - & - & - & - & - & - & - & - & 3 & 7 \\ \text { Dilution } 1: 70.000 \ldots & - & - & - & - & - & - & - & - & - & 1 / 2 & 0 & 10 \\ \text { Dilution } 1: 100.000 \ldots & - & - & - & - & - & - & - & - & - & - & 0 & 10\end{array}$


dans une proportion qui aurait été déterminée par les lois du hasard.

Cette expérience rend évidente les variations des résultats qu'on était en droit de prévoir. Elle démontre encore que, tandis que le nombre de résultats positifs diminue 'orsque la ten Coli diminue, l'intensité de la réaction positive, démontrée par la production de gaz, ne subit qu'une influence légère et irrégulière. Les quantités de gaz dégagées varient pour la dilution $1: 1.000$, de presque nulle (indiquée par + ) à $1 \mathrm{~cm}^{3} 1 / 4$; pour celle de $1: 500$, de presque nulle à $2 \mathrm{~cm}^{3}$; pour celle de 1 : 100 , de 1 à $2 \mathrm{~cm}^{3} 1 / 4$; pour celle de $1: 10$, de 2 à $3 \mathrm{~cm}^{3} 1 / 2$. Pour du lait à teneur élevée en organismes Coli, l'influence de la dilution sur la quantité de gaz dégagée est encore moins prononcée, ainsi que le démontre la série d'épreuves parallèles faites avec des dilutions (voir tableau III).

TABLEAU III.

Gaz en centimòtres cubes.

\begin{tabular}{|c|c|c|c|c|c|c|c|c|c|c|}
\hline & 3 & 3 & 3 & 3 & 3 & 3 & $31 / 4$ & $3 \frac{1 / 4}{4}$ & $31 / 4$ & $31 / 4$ \\
\hline Dilution $1: 250 \ldots \ldots \ldots \ldots$ & 2 & $21 / 4$ & $21 / 2$ & $21 / 2$ & $21 / 2$ & $21 / 2$ & $21 / 2$ & $21 / 2$ & $21 / 2$ & $21 / 2$ \\
\hline 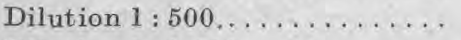 & 2 & $21 / 4$ & $21 / 2$ & $21 / 2$ & $21 / 2$ & $21 / 2$ & $2 \frac{1}{2}$ & $21 / 2$ & $23 / 4$ & \\
\hline . & 2 & 2 & $21 / 4$ & $21 / 2$ & $21 / 2$ & $21 / 2$ & $21 / 4$ & $1 / 2$ & $1 / 2$ & $3 / 4$ \\
\hline & $13 / 4$ & 2 & 2 & 2 & 2 & 2 & $21 / 4$ & $1 / 4$ & $21 / 4$ & \\
\hline & 2 & 2 & 2 & 2 & 2 & 2 & & & $2 \frac{1}{4}$ & \\
\hline il & & $13 / 4$ & $13 / 4$ & 2 & 2 & 2 & & & & \\
\hline 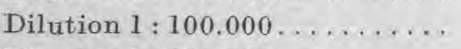 & $11 / 2$ & $11 / 2$ & $1 \frac{1}{2}$ & $11 / 2$ & $11 / 2$ & $11 / 2$ & & & & \\
\hline 1. .000 .000 & $11 / 2$ & $11 / 2$ & $11 / 2$ & $11 / 4$ & $11 / 2$ & $11 / 2$ & 11 & $1 / 2$ & $1 / 2$ & \\
\hline Silution $1: 1.000 .000$ & $11 / 4$ & $11 / 4$ & $11 / 2$ & $13 / 4$ & $13 / 4$ & $13 / 4$ & $13 / 4$ & $3 / 4$ & $3 / 4$ & \\
\hline
\end{tabular}

Enfin, la méthode Pegallac fut encore appliquée à 5 échantillons différents de lait de marché, non dilués ; pour chaque échantillon dix épreuves furent faites, et de grandes variations dans les quantités de gaz dégagées furent constatées (voir tableau IV).

TABLEAU IV.

No

914 Couleur.

Quantité de gaz

938

1041 Couleur..........

Quantité de gaz ...

1117

1214 Couleur..........

Quantité de gaz $\begin{array}{llll}2 & 3 & 4 & 5\end{array}$

$\operatorname{ros} \theta$

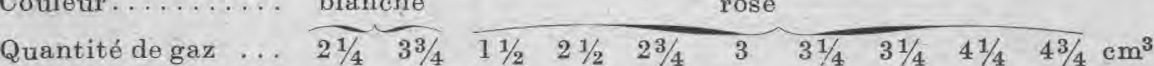

Couleur......... bleue blanche rose

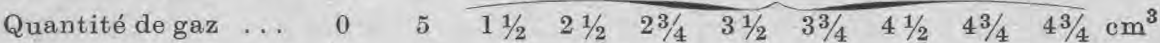
rose

$\begin{array}{llllllllllll}21 / 4 & 21 / 2 & 21 / 2 & 3 & 31 / 4 & 31 / 2 & 31 / 2 & 31 / 2 & 31 / 2 & 31 / 2 & \mathrm{~cm}^{3}\end{array}$


Ces expériences démontrent nettement qu'on ne peut obtenir un résultat pouvant être reproduit avec la méthode Pegallac ; la quantité de gaz dégagée n'est apparemment pas un index de la teneur en Bacterium Coli d'un échantillon de lait. De ce fait, j'ai essayé d'utiliser la réaction de l'indol pour la détermination rapide de la présence d'organismes du groupe Coli.

Avant d'appliquer eette méthode, préconisée par GERSBAcH pour l'analyse de l'eau, par Démeter pour celle du lait, à l'inspection du lait du commerce, je l'ai soumise à un contrôle méticuleux. Il est évident, que lorsque les données fournies par une méthode d'analyse peuvent donner lieu à l'application d'amendes, il faut d'abord la certitude qu'elles présentent un degré d'exactitude satisfaisant. En outre les exigences qu'on est en droit de poser pour le lait d'une exploitation convenablement outillée doivent être fixées.

Je tiens encore à faire remarquer que la méthode examinée ne doit servir qu'à la détermination de la présence du Bacterium Coli, et non, comme les autres méthodes préconisées, à la détermination de la présence de Bacterium Coli plus Bacterium aerogenes, et cela, parce que le Bacterium aerogenes dans le lait n'est pas d'origine féeale. Lorsqu'il s'agit de décider si le lait convient à la préparation de fromage, la détermination de la présence du Bacterium aerogenes a son importance ; pour juger des soins apportés à la production du lait, la teneur en Bacterium Coli fournit de meilleures indications.

Les avis ne sont pas unanimes sur la question de savoir si tous les colibacilles forment de l'indol. BEXTHIEN donne l'avis suivant (III, p. 237) : "La formation d'indol dans des milieux riches en peptone n'est pas non plus une caractéristique permettant d'identifier avec certitude les organismes du groupe Coli. ) KonRICH n'est pas parvenu à démontrer l'existence de cette faculté chez la moitié environ des variétés du groupe Coli qu'il a examinées. Par contre, dans LeHMann (Bacteriolog. Diagnostik, 6e édition, p. 374 d), je trouve : "Une formation abondante de $\mathrm{H}^{2} \mathrm{~S}$ sur peptone, un peu de mercaptan, le plus souvent de l'indol en abondance, des traces d'indol, tout au moins, ne nous ont jamais fait défaut. " A l'endroit qui vient d'être mentionné, BEYTHIEN eontinue : «Toujours le résultat positif de la réaction de l'indol, qui fait défaut pour les cultures des bactéries de la typhoïde et de la paratyphoïde (GÄRTNER), est tellement décisif dans le diagnostic différentiel, qu'on ne peut le négliger nour l'identifieation d'une variété douteuse."

Dans le "Manual of Determinative Bacteriology" (1930) de BERGEY, nous trouvons à la page 318 , les caractéristiques du Bactetium Coli : acidification et coagulation du lait, développement d'acide et de gaz, en présence de dextrose et de lactose, et formation d'in- 
dol. Ce germe est trouvé dans le tractus intestinal de l'homme et de tous les vertébrés.

Dans l'examen du lait, nous eherchons le Bacterium Coli comme représentant des bactéries fécales. Nous cherchons le Bacterium Coli dans le lait pasteurisé et dans le lait-modèle pour conclure de son absence, que cette autre bactérie fécale, le bacille typhique, est également absent. Puisque, selon le Décret sur le Lait (Melkbesluit), la recherche du Bacterium Coli doit être faite par enrichissement dans du bouillon acide, frottis sur agar d'Endo et détermination des cinq caractéristiques mentionnées, parmi lesquelles la formation d'indol, on estime que la présence du Bacterium Coli est seulement démontrée lorsqu'il y a également formation d'indol. Done, sans formation d'indol, il n'y a pas de certitude de la présence du Bacterium Coli.

Il y a cependant d'autres bactéries qui forment de l'indol. Ludwig HEIM les énumère dans son Lehrbuch der Bacteriologie ( $6^{\mathrm{e}}$ et $7^{\mathrm{e}}$ éditions, p. 261). D'après H. ZiPFEL sont indol-positifs : les bactéries Coli et pseudo-dysentériques, les vibrions du choléra et les vibrions similaires (hormis le vibrion Finkler et le vibrion Deneke). En dehors du Bacterium Coli, on ne trouvera pas souvent les espèces mentionnées dans le lait, puisqu'elles ne sont pas des espèces indigènes du pays. Dans le " Manual » de BERGEx, d'autres bactéries, qui forment de l'indol, sont encore mentionnées en dehors du Bacterium Coli. Ainsi le Proteus vulgaris, qui ne forme que peu d'indol, le Pseudomonas, qui forme une substance colorante verte soluble dans l'eau et révèle ainsi immédiatement sa présence; les Sarcina lutea et aurantiaca, qui ne forment que peu d'indol.

S'il est dono admissible, que la production d'indol est provoquée par d'autres bactéries que les organismes Coli, dans la pratique, nous pouvons, pour le lait, - ainsi qu'il est démontré par les expériences qui suivent, - conclure du caractère positif de la réaction de l'indol, que le colibacille est présent. Toujours, sans exception aucune, nous avons déterminé, par la méthode des cultures sur plaques, la présence du Bacterium Coli dans tous les laits examinés, qui donnaient la réaction de l'indol. Il n'en fut pas de même pour la méthode Pegallac; dans $20 \%$ des cas examinés, d'autres organismes que ceux appartenant au groupe Coli donnèrent une réaction positive, tandis que dans aucun cas, une réaction positive de l'indol ne fut fournie par d'autres organismes que ceux appartenant au groupe Coli.

On mentionne cependant des espèces Coli qui ne donnent pas de l'indol, quoique de nombreux auteurs soient d'avis que la dénomination Coli ne peut pas être donnée lorsqu'il n'y a pas formation d'indol. Selon la littérature citée par SINGER (Die Bacteriologische 
Untersuchung des Trinkwassers 1931), de telles espèces se trouvent rarement dans les matières fécales fraîches. Comme i] s'agit ici d'une méthode de détermination de la souillure du lait par des bactéries fécales, il n'y a pas nécessité à tenir compte de ces espèces Coli atypiques; à côté d'elles, seront toujours présentes, beaucoup plus d'espèces Coli normales, formant de l'indol.

La critique émise par BLumenBeEg (Zentralblatt $f$. Bact. I, 107, 386,1928 ) sur l'application de la réaction de l'indol comme épreuve qualitative de la présence d'organismes Coli dans l'eau, par GERsBACH (Zentralblatt f. Bact. I, 88, 145, 1922) et, plus tard, par KoPP (Zentralblatt f. Bact. II, 71, 267, 1927), concerne surtout son application pour l'examen de l'eau, parce que, lors de la présence de peu d'organismes Coli dans un milieu défavorable comme l'eau, où le Bacterium Coli peut dégénérer avant de disparaître, il est possible que la prédominance naturelle $(93,3 \%$ selon les expériences de Blumen berk même) des organismes Coli producteurs d'indol sur les espèces Bacterium Coli « anindolicum ", disparaisse. Pour le lait, les arguments de BLUMENBERG ne peuvent être invoqués.

Les arguments généraux que GERSBACH donne dans son travail, mentionné plus haut, en faveur de l'efficacité de sa méthode pour la détermination dans, la pratique du degré de souillure de l'eau, sont les suivants (voir tableau A).

( Au cours de nos expériences, nous avons, dans tous les cas de réaction positive de l'indol, démontré par des cultures pures, que le Bacterium Coli était le producteur d'indol. Il fut cependant déterminé par des recherches, à données concordantes, de différents auteurs, qu'il existe des espèces Coli qui ne possèdent pas la faculté de produire de l'indol. De ce fait, on pourrait invoquer, que lors de la présence uniquement d'espèces indol-négatives, il est impossible de démontrer leur présence par la réaction de l'indol. Mais nous savons aussi, que dans les défécations de l'homme et du bétail, sont toujours présentes simultanément des espèces indol-positives et indolnégatives, et que les espèces indol-positives prédominent de loin; que, done, dans tous les cas de souillure par des colibacilles, par le développement dans la solution nutritive, on doit trouver également des espèces indol-positives. La démonstration de leur présence par l'épreuve de l'indol ne sera, pas empêchée par les espèces indolnégatives qui seront présentes en même temps. "

Les mêmes arguments s'appliquent au lait, puisque jamais je n'y ai trouvé de l'indol sans Bacterium Coti.

$1 \mathrm{~cm}^{3}$ de chacun des échantillons de lait est mélangé avec $9 \mathrm{~cm}^{3}$ d'une solution de peptone (10 grammes de peptone, 10 grammes de chlorure de sodium et 250 milligrammes de carbonate de sodium; - l'addition de trypsine parut superflue). De ce mélange, $1 \mathrm{~cm}^{3}$ est 
TABLEAU A.

\begin{tabular}{|c|c|c|c|c|c|c|c|c|c|c|c|c|c|}
\hline 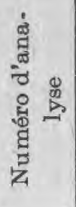 & 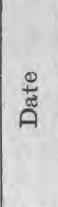 & $\begin{array}{l}\text { Dilution dans solution } \\
\text { de peptone et dans } \\
\text { bouillon acide }\end{array}$ & $\begin{array}{c}\text { Réaction } \\
\text { de l'indol } \\
\text { après } \\
24 \text { heures }\end{array}$ & $\begin{array}{c}\text { Plaques d'agar } \\
\text { d'Endo }\end{array}$ & Pentes d'agar & : & gaz & $\overbrace{\pi}^{\circ}$ & gaz & $\begin{array}{l}\text { Pep- } \\
\text { tone }\end{array}$ & Lait écrémé & Rouge neutre & $\begin{array}{l}\text { Réaction de } \\
\text { l'indol dans } \\
\text { bouillon } \\
\text { acide ou } \\
\text { dans } \\
\text { peptone }\end{array}$ \\
\hline 13629 & $16 / 5$ & $\begin{array}{l}1 / 10 \mathrm{~cm}^{3} \text { bouillon acide } \\
1 / 10 \mathrm{~cm}^{3} \text { peptone } \\
1 / 100 \mathrm{~cm}^{3} \text { peptone } \\
1 / 1.000 \mathrm{~cm}^{3} \text { peptone } \\
1 / 10.000 \mathrm{~cm}^{3} \text { peptone }\end{array}$ & - & $\begin{array}{l}\text { Colonies reflet métal } \\
\text { Colonies reflet métal } \\
\text { Colonies reflet métal } \\
\text { Colonies reflet métal } \\
\text { Colonies reflet métal }\end{array}$ & Développement & + & + & + & + & Trouble & Liquide & Gaz et fluorescence & - \\
\hline 14242 & $22 / 5$ & $\begin{array}{l}1 / 10 \mathrm{~cm}^{3} \text { bouillon acide } \\
1 / 10 \mathrm{~cm}^{3} \text { peptone } \\
1 / 100 \mathrm{~cm}^{3} \text { peptone } \\
1 / 1.000 \mathrm{~cm}^{3} \text { peptone } \\
1 / 10.000 \mathrm{~cm}^{3} \text { peptone }\end{array}$ & $\frac{-}{-}$ & $\begin{array}{l}\text { Peu de développement } \\
\text { Colonies reflet métal } \\
- \\
-\end{array}$ & & & & & & & & & \\
\hline 14330 & $23 / 5$ & $\begin{array}{l}1 / 10 \mathrm{~cm}^{3} \text { bouillon acide } \\
1 / 10 \mathrm{~cm}^{3} \text { peptone } \\
1 / 100 \mathrm{~cm}^{3} \text { peptone } \\
1 / 1.000 \mathrm{~cm}^{3} \text { peptone } \\
1 / 10.000 \mathrm{~cm}^{3} \text { peptone }\end{array}$ & $\frac{1}{-}$ & $\begin{array}{c}\text { Colonies reflet métal } \\
\text { Colonies reflet métal } \\
\text { Colonies reflet métal } \\
- \\
-\end{array}$ & Développement & + & + & + & + & Trouble & Liquide & Gaz et fluorescence & - \\
\hline 15630 & $5 / 6$ & $\begin{array}{l}1 / 10 \mathrm{~cm}^{3} \text { bouillon acide } \\
1 / 10 \mathrm{~cm}^{3} \text { peptone } \\
1 / 100 \mathrm{~cm}^{3} \text { peptone } \\
1 / 1.000 \mathrm{~cm}^{3} \text { peptone } \\
1 / 10.000 \mathrm{~cm}^{3} \text { peptone }\end{array}$ & $\frac{-}{-}$ & $\begin{array}{c}\text { Colonies reflet métal } \\
\text { Colonies reflet métal } \\
\text { Colonies reflet métal } \\
-\end{array}$ & Développement & + & + & + & + & Trouble & Liquide & Gazet fluorescence & - \\
\hline 16266 & $12 / 6$ & $\begin{array}{l}1 / 10 \mathrm{~cm}^{3} \text { bouillon acide } \\
1 / 10 \mathrm{~cm}^{3} \text { peptone } \\
1 / 100 \mathrm{~cm}^{3} \text { peptone } \\
1 / 1.000 \mathrm{~cm}^{3} \text { peptone } \\
1 / 10.000 \mathrm{~cm}^{3} \text { peptone }\end{array}$ & $\frac{-}{-}$ & $\begin{array}{l}\text { Colonies reflet métal } \\
\text { Colonies reflet métal } \\
\text { Colonies reflet métal } \\
\text { Colonies reflet métal } \\
\text { Peu de développement }\end{array}$ & Développement & + & + & + & + & Trouble & Liquide & Gaz et fluorescence & - \\
\hline
\end{tabular}


TABLEAU A (suite).

\begin{tabular}{|c|c|c|c|c|c|c|c|c|c|c|c|c|c|}
\hline 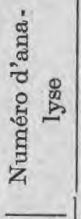 & 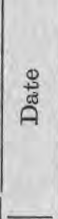 & $\begin{array}{l}\text { Dilution dans solution } \\
\text { de peptone et dans } \\
\text { bouillon acide }\end{array}$ & $\begin{array}{l}\text { Réaction } \\
\text { de l'indol } \\
\text { après } \\
24 \text { heures }\end{array}$ & $\begin{array}{c}\text { Plaques d'agar } \\
\text { d'Endo }\end{array}$ & Pentes d'agar & 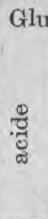 & gaz & $\frac{\overbrace{}}{\pi}$ & gaz & $\begin{array}{l}\text { Pep- } \\
\text { tone }\end{array}$ & Lait écrémé & Rouge neutre & $\begin{array}{l}\text { Réaction de } \\
\text { l'indol dans } \\
\text { bouillon } \\
\text { acide } \\
\text { ou dans } \\
\text { peptone }\end{array}$ \\
\hline 16267 & $12 / 6$ & $\begin{array}{l}1 / 10 \mathrm{~cm}^{3} \text { bouillon acide } \\
1 / 10 \mathrm{~cm}^{3} \text { peptone } \\
1 / 100 \mathrm{~cm}^{3} \text { peptone } \\
1 / 1.000 \mathrm{~cm}^{3} \text { peptone } \\
1 / 10.000 \mathrm{~cm}^{3} \text { peptone }\end{array}$ & $\begin{array}{l}- \\
+ \\
-\end{array}$ & $\begin{array}{l}\text { Colonies reflet métal } \\
\text { Colonies reflet métal } \\
\text { Colonies reflet métal } \\
\text { ? } \\
\text { Peu de développement }\end{array}$ & Développement & $\begin{array}{l}+ \\
+\end{array}$ & $\begin{array}{l}+ \\
+\end{array}$ & $\begin{array}{l}+ \\
+\end{array}$ & + & $\begin{array}{l}\text { Trouble } \\
\text { Trouble }\end{array}$ & $\begin{array}{l}\text { Coagulation } \\
\text { Coagulation }\end{array}$ & $\begin{array}{l}\text { Gaz et fluorescence } \\
\text { Gaz et fluorescence }\end{array}$ & $\begin{array}{l}? \\
+ \\
+\end{array}$ \\
\hline 16268 & $12 / 6$ & $\begin{array}{l}1 / 10 \mathrm{~cm}^{3} \text { bouillon acide } \\
1 / 10 \mathrm{~cm}^{3} \text { peptone } \\
1 / 100 \mathrm{~cm}^{3} \text { peptone } \\
1 / 1.000 \mathrm{~cm}^{3} \text { peptone } \\
1 / 10.000 \mathrm{~cm}^{3} \text { peptone }\end{array}$ & $\begin{array}{l}- \\
+ \\
+ \\
+\end{array}$ & $\begin{array}{l}\text { Colonies à reflet métal } \\
\text { Colonies à reflet métal } \\
\text { Colonies à reflet métal } \\
\text { Colonies à reflet métal } \\
\text { Colonies à reflet métal }\end{array}$ & $\begin{array}{l}\text { Développement } \\
\text { Développement }\end{array}$ & + & + & + & + & Trouble & Coagulation & Gaz et fluorescence & + \\
\hline 16962 & $19 / 6$ & $\begin{array}{l}1 / 10 \mathrm{~cm}^{3} \text { bouillon acide } \\
1 / 10 \mathrm{~cm}^{3} \text { peptone } \\
1 / 100 \mathrm{~cm}^{3} \text { peptone } \\
1 / 1.000 \mathrm{~cm}^{3} \text { peptone } \\
1 / 10.000 \mathrm{~cm}^{3} \text { peptone }\end{array}$ & $\begin{array}{l}- \\
+ \\
+\end{array}$ & $\begin{array}{l}\text { Colonies à reflet métal } \\
\text { Colonies à reflet métal } \\
\text { Colonies à reflet métal } \\
\text { Développement } \\
\text { Développement }\end{array}$ & Développement & + & $\begin{array}{l}+ \\
+\end{array}$ & $\begin{array}{l}+ \\
+\end{array}$ & $\begin{array}{l}+ \\
+\end{array}$ & $\begin{array}{l}\text { Trouble } \\
\text { Trouble }\end{array}$ & $\begin{array}{l}\text { Coagulation } \\
\text { Coagulation }\end{array}$ & $\begin{array}{l}\text { Gaz et fluorescence } \\
\text { Gaz et fluorescence }\end{array}$ & + \\
\hline 17176 & $23 / 6$ & $\begin{array}{l}1 / 10 \mathrm{~cm}^{3} \text { bouillon acide } \\
1 / 10 \mathrm{~cm}^{3} \text { peptone } \\
1 / 100 \mathrm{~cm}^{3} \text { peptone } \\
1 / 1.000 \mathrm{~cm}^{3} \text { peptone } \\
1 / 10.000 \mathrm{~cm}^{3} \text { peptone }\end{array}$ & $\begin{array}{l}+ \\
+ \\
-\end{array}$ & $\begin{array}{l}\text { Colonies à retlet métal } \\
\text { Colonies à reflet métal } \\
\text { Peu de développement }\end{array}$ & Développement & + & + & + & + & Trouble & Coagulation & Gazet fluorescence & + \\
\hline 17956 & $1 / 7$ & $\begin{array}{l}1 / 10 \mathrm{~cm}^{3} \text { bouillon acide } \\
1 / 10 \mathrm{~cm}^{3} \text { peptone } \\
1 / 100 \mathrm{~cm}^{3} \text { peptone } \\
1 / 1.000 \mathrm{~cm}^{3} \text { peptone } \\
1 / 10.000 \mathrm{~cm}^{3} \text { peptone }\end{array}$ & $\begin{array}{l}- \\
- \\
-\end{array}$ & $\begin{array}{c}\text { ? } \\
\text { Colonies à reflet métal } \\
\text { Colonies à reflet métal } \\
- \\
-\end{array}$ & Développement & + & + & + & + & Trouble & Coagulation & Gaz et fluorescence & + \\
\hline
\end{tabular}


TABLEAU A (suite).

\begin{tabular}{|c|c|c|c|c|c|c|c|c|c|c|c|c|c|}
\hline 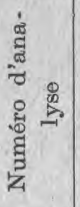 & $\frac{9}{\Phi^{\circ}}$ & $\begin{array}{l}\text { Dilution dans solution } \\
\text { de peptone et dans } \\
\text { bouillon acide }\end{array}$ & $\begin{array}{c}\text { Réaction } \\
\text { de l'indol } \\
\text { après } \\
24 \text { heures }\end{array}$ & $\begin{array}{c}\text { Plaques d'agar } \\
\text { d'Endo }\end{array}$ & Pentes d'agar & $\frac{1}{\frac{\pi}{0}}$ & gaz & ֻँّ & gaz & $\begin{array}{l}\text { Pep- } \\
\text { tone }\end{array}$ & Lait écrémé & Rouge neutre & $\begin{array}{l}\text { Réaction de } \\
\text { l'indol dans } \\
\text { bouillon } \\
\text { acide } \\
\text { ou dans } \\
\text { peptone }\end{array}$ \\
\hline 17957 & $1 / 7$ & $\begin{array}{l}1 / 10 \mathrm{~cm}^{3} \text { bouillon acide } \\
1 / 10 \mathrm{~cm}^{3} \text { peptone } \\
1 / 100 \mathrm{~cm}^{3} \text { peptone } \\
1 / 1.000 \mathrm{~cm}^{3} \text { peptone } \\
1 / 10.000 \mathrm{~cm}^{3} \text { peptone }\end{array}$ & $\begin{array}{l}+ \\
+ \\
- \\
-\end{array}$ & $\begin{array}{c}? \\
\text { Colonies à reflet métal } \\
- \\
-\end{array}$ & Déreloppement & + & + & + & + & Trouble & Coagulation & Gaz et fluorescence & + \\
\hline 18221 & $3 / 7$ & $\begin{array}{l}1 / 10 \mathrm{~cm}^{3} \text { bouillon acide } \\
1 / 10 \mathrm{~cm}^{3} \text { peptone } \\
1 / 100 \mathrm{~cm}^{3} \text { peptone } \\
1 / 1.000 \mathrm{~cm}^{3} \text { peptone } \\
1 / 10.000 \mathrm{~cm}^{3} \text { peptone }\end{array}$ & $\begin{array}{l}- \\
+ \\
+ \\
-\end{array}$ & $\begin{array}{l}\text { Colonies à reflet métal } \\
\text { Colonies à reflet métal } \\
\text { Colonies à reflet métal } \\
\text { Colonies à reflet métal } \\
\text { Peu de développement }\end{array}$ & Développement & + & + & + & + & Trouble & Coagulation & Gaz et fluorescence & $\begin{array}{l}+ \\
+\end{array}$ \\
\hline 18553 & $8 / 7$ & $\begin{array}{l}1 / 10 \mathrm{~cm}^{3} \text { bouillon acide } \\
1 / 10 \mathrm{~cm}^{3} \text { peptone } \\
1 / 100 \mathrm{~cm}^{3} \text { peptone } \\
1 / 1.000 \mathrm{~cm}^{3} \text { peptone } \\
1 / 10.000 \mathrm{~cm}^{3} \text { peptone }\end{array}$ & $\begin{array}{l}- \\
+ \\
+\end{array}$ & $\begin{array}{l}\text { Colonies à reflet métal } \\
\text { Colonies à reflet métal } \\
\text { Colonies à reflet métal } \\
\text { Colonies à reflet métal } \\
\text { Peu de développement }\end{array}$ & $\begin{array}{l}\text { Développement } \\
\text { Développement }\end{array}$ & + & + & + & + & Trouble & $\begin{array}{l}\text { Coagulation } \\
\text { Coagulation }\end{array}$ & $\begin{array}{l}\text { Gaz et fluorescence } \\
\text { Gaz et fluorescence }\end{array}$ & $\begin{array}{l}+ \\
+\end{array}$ \\
\hline 18631 & $9 / 7$ & $\begin{array}{l}1 / 10 \mathrm{~cm}^{3} \text { bouillon acide } \\
1 / 10 \mathrm{~cm}^{3} \text { peptone } \\
1 / 100 \mathrm{~cm}^{3} \text { peptone } \\
1 / 1.000 \mathrm{~cm}^{3} \text { peptone } \\
1 / 10.000 \mathrm{~cm}^{3} \text { peptone }\end{array}$ & $\begin{array}{l}- \\
+ \\
-\end{array}$ & $\begin{array}{l}\text { Colonies à reflet métal } \\
\text { Colonies à reflet métal } \\
\text { Colonies à reflet métal } \\
\text { Peu de développement } \\
\text { Développement }\end{array}$ & Développement & $\begin{array}{l}+ \\
+\end{array}$ & $\begin{array}{l}+ \\
+\end{array}$ & + & + & Trouble & $\begin{array}{l}\text { Coagulation } \\
\text { Coagulation }\end{array}$ & $\begin{array}{l}\text { Gaz et fluorescence } \\
\text { Gaz et fluorescence }\end{array}$ & $\begin{array}{l}+ \\
+\end{array}$ \\
\hline
\end{tabular}


TABLEAU A (Fin).

\begin{tabular}{|c|c|c|c|c|c|c|c|c|c|c|c|c|c|}
\hline 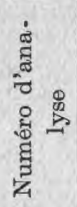 & 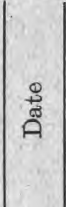 & $\begin{array}{l}\text { Dilution dans solution } \\
\text { de peptone et dans } \\
\text { bouillon acide }\end{array}$ & $\begin{array}{c}\text { Réaction } \\
\text { de l'indol } \\
\text { après } \\
24 \text { heures }\end{array}$ & $\begin{array}{l}\text { Plaques d'agar } \\
\text { d'Endo }\end{array}$ & Pentes d'agar & : & $\cos \theta$ & $\frac{8}{\overparen{\pi}}$ & gaz & $\begin{array}{l}P \in p- \\
\text { tone }\end{array}$ & Lait écrémé & Rouge neutre & $\begin{array}{l}\text { Réaction de } \\
\text { l'indol dans } \\
\text { bouillon } \\
\text { acide } \\
\text { ou dans } \\
\text { peptone }\end{array}$ \\
\hline 18880 & $15 / 7$ & $\begin{array}{l}1 / 10 \mathrm{~cm}^{3} \text { bouillon acide } \\
1 / 10 \mathrm{~cm}^{3} \text { peptone } \\
1 / 100 \mathrm{~cm}^{3} \text { peptone } \\
1 / 1.000 \mathrm{~cm}^{3} \text { peptone } \\
1 / 10.000 \mathrm{~cm}^{3} \text { peptone }\end{array}$ & $\begin{array}{l}- \\
+ \\
+ \\
-\end{array}$ & $\begin{array}{l}\text { Développement } \\
\text { Colonies à reflet métal } \\
\text { Colonies à reflet métal } \\
\text { Développement } \\
\quad\end{array}$ & Développement & + & + & + & + & Trouble & Coagulation & Gaz et fluorescence & + \\
\hline 19299 & $22 / 7$ & $\begin{array}{l}1 / 10 \mathrm{~cm}^{3} \text { bouillon acide } \\
1 / 10 \mathrm{~cm}^{3} \text { peptone } \\
1 / 100 \mathrm{~cm}^{3} \text { peptone } \\
1 / 1.000 \mathrm{~cm}^{3} \text { peptone } \\
1 / 10.000 \mathrm{~cm}^{3} \text { peptone }\end{array}$ & $\begin{array}{l}- \\
+ \\
+?\end{array}$ & $\begin{array}{l}\text { Colonies à reflet métal } \\
\text { Colonies à reflet métal } \\
\text { Colonies à reflet métal } \\
\text { Colonies à reflet métal } \\
\text { Colonies pâles }\end{array}$ & Développement & $\begin{array}{l}+ \\
+\end{array}$ & + & + & + & $\begin{array}{l}\text { Trouble } \\
\text { Trouble }\end{array}$ & $\begin{array}{l}\text { Coagulation } \\
\text { Coagulation }\end{array}$ & $\begin{array}{l}\text { Gaz et fluorescence } \\
\text { Gaz et fluorescence }\end{array}$ & $\begin{array}{l}+ \\
+\end{array}$ \\
\hline 19438 & $23 / 7$ & $\begin{array}{l}1 / 10 \mathrm{~cm}^{3} \text { bouillon acide } \\
1 / 10 \mathrm{~cm}^{3} \text { peptone } \\
1 / 100 \mathrm{~cm}^{3} \text { peptone } \\
1 / 1.000 \mathrm{~cm}^{3} \text { peptone } \\
1 / 10.000 \mathrm{~cm}^{3} \text { peptone }\end{array}$ & $\begin{array}{l}- \\
+ \\
-\end{array}$ & $\begin{array}{l}\text { Colonies à reflet métal } \\
\text { Colonies à reflet métal } \\
\text { Colonies à reflet métal } \\
\text { Développement } \\
\text { Peu de développement }\end{array}$ & Développement & $\begin{array}{l}+ \\
+\end{array}$ & + & + & + & $\begin{array}{l}\text { Trouble } \\
\text { Trouble }\end{array}$ & $\begin{array}{l}\text { Coagulation } \\
\text { Coagulation }\end{array}$ & $\begin{array}{l}\text { Gaz et fluorescence } \\
\text { Gaz et fluorescence }\end{array}$ & $\begin{array}{l}+ \\
+\end{array}$ \\
\hline
\end{tabular}


mélangé avee $9 \mathrm{~cm}^{3}$ de la solution de peptone, de façon à obtenir les dilutions suivantes : $1 / 10,1 / 100,1 / 1.000,1 / 10.000,1 / 100.000$.

Après conservation à $37^{\circ} \mathrm{C}$. pendant 24 heures, on recherche dans de petites quantités de ces dilutions, dans des éprouvettes, s'il y a de l'indol, par la méthode d'Ehrlich (Indol A : paradiméthylamidobenzaldéhyde, 2 grammes ; alcool à $96^{\circ}, 190 \mathrm{~cm}^{3}$, et $\mathrm{HCl}$ à $25 \%, 40 \mathrm{~cm}^{3}$. Indol B : une solution saturée de persulfate de calcium).

Ainsi que le montre le tableau $\mathrm{A}$, la réaction est généralement négative pour la dilution $1 / 10$ (même en présence de Bacterium Coli). Il y a apparemment inhibition de la réaction, soit par la coagulation de constituants du lait, soit par la présence de lactose. Dans la dilution 1/100 et les dilutions plus grandes, la réaction est positive lors de la présence du Bacterium Coli.

Pour le bon lait-modèle et le bon lait pasteurisé, la réaction est négative à la dilution $1 / 100$. Pour le lait cru ordinaire, la réaction est presque toujours positive à $1 / 100$; en règle générale, également à $1 / 1.000$. Si la production du lait est malpropre, la réaction de l'indol est encore positive à $1 / 10.000$ et même à $1 / 100.000$.

Les expériences, dont un aperçu est donné ici, furent exécutées systématiquement de la façon suivante :

D'abord, une culture de $1 \mathrm{~cm}^{3}$ du lait fut faite dans du bouillon acide, selonla méthode de Ringeling, en vue de déterminer s'il y avait présence de Bacterium Coli dans le lait; puis, transfert sur agar d'Endo. Une colonie fut transplantée sur agar-agar, et ses caractéristiques furent déterminées (glucose : acide et gaz; lactose : acide et gaz ; lait écrémé : coagulation ; rouge neutre : fluorescence et gaz ; peptone : trouble et indol). En plus, il fut additionné $1 \mathrm{~cm}^{3}$ de chaque échantillon de lait à $9 \mathrm{~cm}^{3}$ d'une solution aqueuse de peptone, et chaque fois $1 \mathrm{~cm}^{3}$ de cinq solutions décimales consécutives du lait au moyen de la solution aqueuse de peptone, ce qui donna des dilutions à $1 / 10^{\mathrm{e}}, 1 / 100^{\mathrm{e}}, 1 / 1.000^{\mathrm{e}}, 1 / 10.000^{\mathrm{e}}, 1 / 100.000^{\mathrm{e}}$ de centimètre eube de lait pour $10 \mathrm{~cm}^{3}$ de solution aqueuse de peptone. Après 24 et 48 heures la réaction de l'indol fut effectuée, et en plus, de chacune des cultures dans la solution aqueuse de peptone, il fut fait des cultures sur plaques d'agar d'Endo, et les caractéristiques d'une des colonies obtenues sur ces cultures, furent déterminées.

Lorsqu'on procède ainsi, il arrive parfois qu'on trouve le Bacterium Coli dans $1 \mathrm{~cm}^{3}$ par la méthode de Ringeling, et qu'on ne le trouve pas par la nouvelle méthode : par exemple, dans les cas, où la teneur en Bacterium Coli n'est que très peu élevée. Il est arrivé aussi, que dans une dilution déterminée, on ne soit pas parvenu à démontrer la formation d'indol par la nouvelle méthode, et que, lors du transfert de la solution aqueuse de peptone sur agar d'Endo, 
on soit parvenu à eultiver des organismes Coli qui possédaient la faculté de produire de l'indol.

En vue de démontrer comment ces différentes éventualités peuvent se produire, les résultats complets obtenus pour 17 des 35 laits-modèles examinés sont réunis dans le tableau A : en fait, les laits pour lesquels toutes les réactions ne furent pas négatives et qui ne donnèrent pas non plus de colonies à reflet métallique. Pour tous les cas qui ont donné une réaction positive de l'indol, toutes les autres caractéristiques du Bacterium Coli furent contrôlées et trouvées positives.

Le degré de souillure, par le Bacterium Coli, des laits-modèles examinés peut être estimé, d'après la dilution, au moyen de la solution aqueuse de peptone, dans laquelle on parvient à déterminer après 24 heures, la présence d'indol. Des 33 échantillons, 22 ne donnèrent pas d'indol, 5 en donnèrent dans $1 / 100^{\circ}$ de centimètre cube, 4 dans $1 / 1.000^{e}, 2$ dans $1 / 10.000^{e}$. Parmi ces six derniers échantillons, 5 donnèrent du Bacterium Coli dans du bouillon acide ensemencé de la dilution à $1 / 10^{\mathrm{e}}$ de centimètre cube de lait, tandis que cela ne se présenta que pour deux des cinq échantillons dont $1 / 100^{e}$ de centimètre cube donna la réaction de l'indol.

Une des conditions à exiger pour le lait-modèle : seulement une légère production d'indol à la dilution à $1 / 100^{\circ}$ de centimètre cube, pas de production d'indol à celle à $1 / 1.000^{\circ}$, eorrespond done relativement bien avee la certitude qu'on ne parviendra pas à cultiver le Bacterium Coli dans du bouillon acide avee la dilution à $1 / 10^{\mathrm{e}}$. La pratique démontre cependant qu'on peut sans inconvénient exiger qu'il n'y ait pas formation d'indol avec $1 / 100^{\circ}$ de centimètre cube de lait.

L'examen, par les mêmes méthodes, de 50 échantillons de lait pasteurisé a démontré que 46 d'entre eux ne contenaient pas de Bacterium Coli, selon les résultats fournis par la culture dans une solution aqueuse de peptone et par la culture dans du bouillon acide ; pour les 4 échantillons fournissant des données positives, les résultats sont indiqués au tableau $\mathrm{B}$.

La certitude que, par la culture en bouillon acide, on ne parviendra pas à démontrer dans $1 \mathrm{~cm}^{3}$ de lait, la présence de Bacterium Coli, correspond done relativement bien avec celle qu'on ne parviendra pas à déterminer la présence d'indol après 24 heures dans $1 / 100^{\circ}$ de centimètre củbe dans une solution aqueuse de peptone.

Par les mêmes méthodes, il fut encore examiné un grand nombre d'échantillons de lait cru de différents producteurs, dont la production n'avait pas été l'objet de soins spéciaux. Pour ainsi dire sans exception, le Bacterium Coli fut trouvé, pour tous les cas, lors de culture de $1 \mathrm{~cm}^{3}$ dans du bouillon acide. Le degré de souillure, 
TABLEAU B.

\begin{tabular}{c|c|c|c}
\hline \hline $\begin{array}{c}\text { Numéro } \\
\text { d'analyse }\end{array}$ & Date & $\begin{array}{c}\text { Solution de peptone dans laquelle } \\
\text { il y eut encore formation d'indol } \\
\text { après } 24 \text { heures }\end{array}$ & $\begin{array}{c}\text { Bacterium } \\
\text { Coli dans } \\
1 \mathrm{~cm}^{3} \text { de lait } \\
\text { et bouilon } \\
\text { acide }\end{array}$ \\
\hline 23962 & $23 / 9$ & $1 / 100$ de centimètre cube & - \\
24475 & $29 / 9$ & $1 / 1.000$ de centimètre cube & - \\
$27298^{\circ}$ & $27 / 10$ & $1 / 100$ de centimètre cube & + \\
27300 & $27 / 10$ & $1 / 1.000$ de centimètre eube & + \\
\hline \hline
\end{tabular}

déterminé selon la dilution dans laquelle après 24 heures il fut possible de démontrer la présence d'indol, était très variable pour les différents échantillons. La répartition des échantillons, selon la dilution décimale dans laquelle il y avait encore formation d'indol, était la suivante pour un total de 160 échantillons :

Indol : rien, 19 ; dans $1 / 100^{\circ}$ de centimètre cube, 15 ; dans $1 / 1.000^{\mathrm{e}}, 29$; dans $1 / 10.000^{\mathrm{e}}, 38$; dans $1 / 100.000^{\mathrm{e}}, 59$.

Donc, sur 160 échantillons, 19 présentaient les conditions requises, concernant le Bacterium Coli, pour le lait-modèle; 15 échantillons contenaient 10 fois autant, 29 échantillons 100 fois autant de Bacterium Coli. De 97 échantillons, la teneur en organismes Coli était encore au moins dix fois aussi élevée. Puisque ces données démontrent qu'il est pratiquement possible pour des producteurs ordinaires de fournir du lait qui ne contient que peu d'organismes Coli (décelable dans $1 / 1.000^{\circ}$ de centimètre cube), on peut exiger la fourniture d'un tel lait de tous les producteurs. Cette exigence serait la suivante : pas de formation d'indol après 24 heures dans $10 \mathrm{~cm}^{3}$ d'une solution aqueuse de peptone additionnés de $1 / 10.000^{\mathrm{e}}$ de centimètre cube de lait.

Les résultats obtenus au cours de ces expériences démontrent la possibilité d'utilisation de cette nouvelle méthode de titrage du Bacterium Coli pour l'estimation des soins apportés à la production du lait ordinaire, du lait-modèle et de la garantie fournie par le lait pasteurisé, dès qu'il aura été démontré, qu'il est possible d'obtenir plusieurs fois des résultats similaires avec les mêmes échantillons de lait, et que lors de dilution d'un lait contenant des organismes Coli au moyen de lait pasteurisé, les données du titrage baissent.

Tel est le cas. J'ai fait le titrage de 5 échantillons de lait ; de chaque échantillon, il fut examiné 10 fractions, et chaque fois, 
il fut constaté une concordance pratiquement complète entre les résultats obtenus poưr les 10 fractions d'un même échantillon, ainsi que le démontre le tableau $\mathrm{C}$.

TABLEA'U C.

Lait cru : Réaction de l'indol après 24 heures.

\begin{tabular}{|c|c|c|c|c|c|c|c|c|c|c|c|}
\hline Numéro d'analyse & $\begin{array}{l}\text { Dilution dans } \\
\text { solution de peptone }\end{array}$ & I & II & III & IV & V & VI & VII & VIII & IX & $\mathrm{x}$ \\
\hline R 2899 & $\begin{array}{l}1 / \\
1 / 100 \\
1 / 1.000 \\
1 / 10.000 \\
1 / 100.000\end{array}$ & $\begin{array}{l}- \\
+ \\
+ \\
+ \\
-\end{array}$ & $\begin{array}{l}- \\
+ \\
+ \\
+ \\
-\end{array}$ & $\begin{array}{l}- \\
+ \\
+ \\
+ \\
-\end{array}$ & $\begin{array}{l}- \\
+ \\
+ \\
+ \\
\end{array}$ & $\begin{array}{l}- \\
+ \\
+ \\
? \\
-\end{array}$ & $\begin{array}{l}- \\
+ \\
+ \\
+ \\
-\end{array}$ & $\begin{array}{l}- \\
+ \\
+ \\
+ \\
-\end{array}$ & $\begin{array}{l}- \\
+ \\
+ \\
+ \\
-\end{array}$ & $\begin{array}{l}- \\
+ \\
+ \\
+ \\
-\end{array}$ & $\begin{array}{l}- \\
+ \\
+ \\
? \\
-\end{array}$ \\
\hline R 3507 . & $\begin{array}{l}1 / 10 \\
1 / 100 \\
1 / 1.000 \ldots . \\
1 / 10.000 \\
1 / 100.000\end{array}$ & $\begin{array}{l}- \\
+ \\
+ \\
+ \\
+\end{array}$ & $\begin{array}{l}- \\
+ \\
+ \\
+ \\
-\end{array}$ & $\begin{array}{l}- \\
+ \\
+ \\
+ \\
+\end{array}$ & $\begin{array}{l}- \\
+ \\
+ \\
+ \\
-\end{array}$ & $\begin{array}{l}- \\
+ \\
+ \\
+ \\
+\end{array}$ & $\begin{array}{l}- \\
+ \\
+ \\
+ \\
+\end{array}$ & $\begin{array}{l}- \\
+ \\
+ \\
+ \\
+\end{array}$ & $\begin{array}{l}- \\
+ \\
+ \\
+ \\
+\end{array}$ & $\begin{array}{l}- \\
+ \\
+ \\
+ \\
+\end{array}$ & $\begin{array}{l}- \\
+ \\
+ \\
+ \\
+\end{array}$ \\
\hline $\mathrm{R} 3523$ & $\begin{array}{l}1 / 10 \\
1 / 100 \\
1 / 1.000 \\
1 / 10.000 \\
1 / 100.000\end{array}$ & $\begin{array}{l}- \\
+ \\
+ \\
+ \\
+\end{array}$ & $\begin{array}{l}- \\
+ \\
+ \\
+ \\
+\end{array}$ & $\begin{array}{l}- \\
+ \\
+ \\
+ \\
+\end{array}$ & $\begin{array}{l}- \\
+ \\
+ \\
+ \\
+\end{array}$ & $\begin{array}{l}- \\
+ \\
+ \\
+ \\
+\end{array}$ & $\begin{array}{l}- \\
+ \\
+ \\
+ \\
+\end{array}$ & $\begin{array}{l}- \\
+ \\
+ \\
+ \\
+\end{array}$ & $\begin{array}{l}- \\
+ \\
+ \\
+ \\
+\end{array}$ & $\begin{array}{l}- \\
+ \\
+ \\
+ \\
+\end{array}$ & $\begin{array}{l}- \\
+ \\
+ \\
+ \\
+\end{array}$ \\
\hline R 3945 & $\begin{array}{l}1 / 10 \\
1 / 100 \\
1 / 1.000 \\
1 / 10.000 \\
1 / 100.000\end{array}$ & $\begin{array}{l}? \\
+ \\
? \\
- \\
\end{array}$ & $\begin{array}{l}+ \\
+ \\
+ \\
? \\
-\end{array}$ & $\begin{array}{l}? \\
+ \\
+ \\
+ \\
+\end{array}$ & $\begin{array}{l}- \\
+ \\
+ \\
+ \\
-\end{array}$ & $\begin{array}{l}+ \\
+ \\
+ \\
+ \\
-\end{array}$ & $\begin{array}{l}+ \\
+ \\
+ \\
+ \\
-\end{array}$ & $\begin{array}{l}+ \\
+ \\
+ \\
+ \\
-\end{array}$ & $\begin{array}{l}- \\
+ \\
+ \\
+ \\
-\end{array}$ & $\begin{array}{l}+ \\
+ \\
+ \\
+ \\
-\end{array}$ & $\begin{array}{l}- \\
+ \\
+ \\
+ \\
?\end{array}$ \\
\hline R 3956 & $\begin{array}{l}1 / 10 \\
1 / 100 \\
1 / 1.000 \\
1 / 10.000 \\
1 / 100.000\end{array}$ & $\begin{array}{l}- \\
+ \\
+ \\
-\end{array}$ & $\begin{array}{l}- \\
+ \\
+ \\
-\end{array}$ & $\begin{array}{l}? \\
+ \\
+ \\
- \\
-\end{array}$ & $\begin{array}{l}+ \\
+ \\
+ \\
- \\
-\end{array}$ & $\begin{array}{l}- \\
+ \\
? \\
- \\
-\end{array}$ & $\begin{array}{l}- \\
+ \\
? \\
- \\
-\end{array}$ & $\begin{array}{l}? \\
+ \\
+ \\
- \\
-\end{array}$ & $\begin{array}{l}? \\
+ \\
+ \\
- \\
-\end{array}$ & $\begin{array}{l}+ \\
+ \\
+ \\
- \\
-\end{array}$ & $\begin{array}{l}+ \\
+ \\
+ \\
-\end{array}$ \\
\hline
\end{tabular}

En plus, de chacun de ces cinq échantillons de lait, j'ai mélangé $10 \mathrm{~cm}^{3}$ avec $90 \mathrm{~cm}^{3}$ de lait pasteurisé, et, de ce mélange, j'ai encore mélangé $10 \mathrm{~cm}^{3}$ avec $90 \mathrm{~cm}^{3}$ de lait pasteurisé, et ainsi de suite.

Il fut constaté, lors du titrage du Bacterium Coli de ces dilutions, que les résultats obtenus présentaient les rapports prévus avec le degré de souillure par le Bacterium Coli du lait original. Les résultats de ces expériences en série sont donnés au tableau $\mathrm{D}$. 
TABLEAU D.

Indol après 24 heures.

\begin{tabular}{|c|c|c|c|c|c|c|}
\hline Lait pasteurisé & $\begin{array}{c}\text { Dilution dans } \\
\text { solution de peptone }\end{array}$ & 1 & 2 & 3 & 4 & 5 \\
\hline 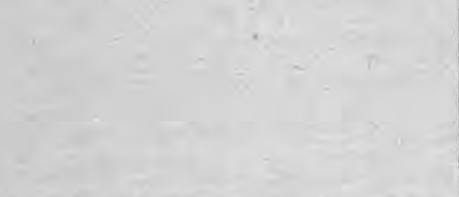 & $\begin{array}{l}1 / 10 \\
1 / 100 \\
1 / 1.000 \\
1 / 10.000 \\
1 / 100.000\end{array}$ & $\begin{array}{l}- \\
- \\
- \\
-\end{array}$ & $\begin{array}{l}- \\
- \\
- \\
-\end{array}$ & $\begin{array}{l}- \\
- \\
-\end{array}$ & $\begin{array}{l}- \\
- \\
- \\
-\end{array}$ & $\begin{array}{l}- \\
- \\
-\end{array}$ \\
\hline$=$ & & R $\begin{array}{c}1 \\
2899\end{array}$ & $\begin{array}{l}2 \\
\text { R } 3507\end{array}$ & $\begin{array}{c}3 \\
\text { R } 3523\end{array}$ & $\begin{array}{ll} & 4 \\
\text { R } & 3945\end{array}$ & $\begin{array}{c}5 \\
3956\end{array}$ \\
\hline $\begin{array}{l}10 \mathrm{~cm}^{3} \text { lait cru et } 90 \mathrm{~cm}^{3} \text { lait pas- } \\
\text { teurisé }\end{array}$ & $\begin{array}{l}1 / 10 \\
1 / 100 \\
1 / 1.000 \\
1 / 10.000 \\
1 / 100.000\end{array}$ & $\begin{array}{l}- \\
+ \\
+ \\
+ \\
-\end{array}$ & $\begin{array}{l}- \\
+ \\
+ \\
-\end{array}$ & $\begin{array}{l}- \\
+ \\
+ \\
+ \\
+\end{array}$ & $\begin{array}{l}+ \\
+ \\
+ \\
- \\
-\end{array}$ & $\begin{array}{l}? \\
+ \\
- \\
- \\
-\end{array}$ \\
\hline $\begin{array}{l}10 \mathrm{~cm}^{3} \text { mélange précédent et } \\
90 \mathrm{~cm}^{3} \text { lait pasteurisé }\end{array}$ & $\begin{array}{l}1 / 10 \\
1 / 100 \\
1 / 1.000 \\
1 / 10.000 \\
1 / 100.000\end{array}$ & $\begin{array}{l}- \\
+ \\
+ \\
-\end{array}$ & $\begin{array}{l}- \\
+ \\
- \\
-\end{array}$ & $\begin{array}{l}- \\
+ \\
+ \\
+ \\
+\end{array}$ & $\begin{array}{l}- \\
+ \\
-\end{array}$ & $\begin{array}{l}- \\
- \\
- \\
-\end{array}$ \\
\hline $\begin{array}{l}10 \mathrm{~cm}^{3} \text { mélange précédent et } \\
90 \mathrm{~cm}^{3} \text { lait pasteurisé }\end{array}$ & $\begin{array}{l}1 / 10 \\
1 / 100 \\
1 / 1.000 \\
1 / 10.000 \\
1 / 100.000 \\
1 / 100.000\end{array}$ & $\begin{array}{l}- \\
- \\
- \\
-\end{array}$ & $\begin{array}{l}+ \\
- \\
- \\
-\end{array}$ & $\begin{array}{l}- \\
+ \\
- \\
-\end{array}$ & $\begin{array}{l}- \\
- \\
- \\
-\end{array}$ & $\begin{array}{l}- \\
- \\
- \\
-\end{array}$ \\
\hline $\begin{array}{l}10 \mathrm{~cm}^{3} \text { mélange précédent et } \\
90 \mathrm{~cm}^{3} \text { lait pasteurisé }\end{array}$ & $\begin{array}{l}1 / 10 \\
1 / 100 \\
1 / 1.000 \\
1 / 10.000 \\
1 / 100.000\end{array}$ & $\begin{array}{l}-- \\
- \\
-\end{array}$ & $\begin{array}{l}- \\
- \\
- \\
-\end{array}$ & $\begin{array}{l}- \\
- \\
- \\
-\end{array}$ & $\begin{array}{l}- \\
- \\
-\end{array}$ & $\begin{array}{l}- \\
- \\
-\end{array}$ \\
\hline
\end{tabular}

Je propose donc d'estimer la teneur en Bacterium Coli fécal frais du lait, d'après la dilution dans laquelle la réaction de l'indol fournit des résultats positifs, étant convaincu que le degré moyen de la formation d'indol par les organismes Coli des matières fécales de différentes vaches ne sera pas notablement différent. 
Je crois pouvoir conclure, que la réaction de l'indol, appliquée comme il a été prescrit, permettra de décider en 24 heures de temps, si la production du lait (et du lait-modèle) a été l'objet de soins convenables, si le chauffage du lait pasteurisé a été d'assez longue durée et si sa température a été assez élevée.

Toutes les expériences faites démontrent qu'on peut exiger : pas de formation d'indol dans $1 / 10.000^{\mathrm{e}}$ de centimètre cube pour le lait de marché, et pas de formation d'indol dans $1 / 100^{\circ}$ de centimètre cube pour le lait-modèle et le lait pasteurisé.

A Amsterdam, la méthode a été introduite, sur cette base, dans le contrôle quotidien du lait. Tant dans cette ville que dans d'autres villes néerlandaises, qui l'ont adoptée, il a été démontré que les limites préconisées ici peuvent être maintenues. Les nombreux avertissements émanant du laboratoire, - il n'y eut pas encore d'application d'amendes, - concernant une teneur trop élevée en Bacterium Coli, ont eu comme conséquence une amélioration progressive.

La première année, le pourcentage de lait défectueux à ce point de vue fut de 58,5 ; la deuxième année, 41,3 ; tandis que la troisième année (1933), parmi les 1.497 échantillons sur lesquels la méthode fut appliquée, seulement 480 , soit $32,1 \%$, furent trouvés défectueux. En 1934, ce pourcentage fut de 25 .

Le tableau suivant montre comment parmi les 1.497 échantillons examinés du cours de l'année 1933, les échantillons défectueux sont répartis sur les différents mois de l'année.

TITRAGE DU « BACTERIUM COLI " DANS 1.497 ECHANTILLONS DE LAIT DE MARCHÉ AU COURS DE L'ANNÉE 1933.

\begin{tabular}{|c|c|c|c|c|c|c|c|}
\hline & \multirow{2}{*}{$\begin{array}{c}\text { Coli } \\
\text { négatif } \\
\text { dans }\end{array}$} & \multicolumn{6}{|c|}{ Coli positif dans : } \\
\hline - & & $1 / 10$ & $1 / 100$ & $1 / 1.000$ & $1 / 10.000$ & $1 / 100.000$ & $1 / 1.000 .000$ \\
\hline Janvier .............. & 42 & 7 & 43 & 32 & 7 & 4 & 2 \\
\hline Février $\ldots \ldots \ldots \ldots \ldots$ & 37 & 11 & 50 & 23 & 4 & 2 & 2 \\
\hline Mars................ & 35 & 9 & 54 & 28 & 7 & 3 & 2 \\
\hline Avril $\ldots . . . \ldots \ldots \ldots$ & 31 & 6 & 37 & 30 & 12 & 7 & 7 \\
\hline Mai................ & 21 & 3 & 24 & 25 & 15 & 13 & 10 \\
\hline Juin $\ldots \ldots \ldots \ldots \ldots \ldots$ & 8 & 1 & 19 & 21 & $2 \mathrm{I}$ & 19 & 23 \\
\hline Juillet .............. & 1 & 1 & 11 & 26 & 17 & 15 & 31 \\
\hline Août $\ldots \ldots \ldots \ldots \ldots \ldots$ & 2 & 1 & 17 & 20 & 22 & 33 & 35 \\
\hline Septembre............ & 2 & 2 & 16 & 25 & 21 & 18 & 41 \\
\hline Octobre $\ldots \ldots \ldots \ldots$. & 11 & 5 & 27 & 28 & 20 & 19 & 19 \\
\hline Novembre ........... & 34 & 14 & 48 & 35 & 14 & 3 & 4 \\
\hline Décembre ............ & 29 & 11 & 28 & 26 & 6 & 2 & - \\
\hline Total $\ldots \ldots \ldots \ldots \ldots$ & 253 & 71 & 374 & 319 & 166 & 138 & 175 \\
\hline
\end{tabular}


L'application de la méthode à dulait-modèle au cours de l'année. 1933 fournit les résultats suivants :

TITRAGE DU " BACTERIUM COLI " DE 182 ECHANTHLLNS DE LAIT MODELE AU COURS DE L'ANNÉE 1933.

\begin{tabular}{|c|c|c|c|c|c|}
\hline 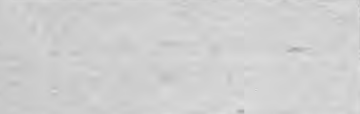 & $\begin{array}{c}\text { Coli } \\
\text { négatif } \\
\text { dans }\end{array}$ & $1 / 10$ & $1 / 100$ & $1 / 1.000$ & $1 / 10.000$ \\
\hline Janvier $\ldots \ldots \ldots \ldots \ldots$ & 11 & 2 & 2 & - & 一 \\
\hline Février $\ldots \ldots \ldots \ldots \ldots$ & 17 & 1 & 1 & 1 & - \\
\hline Mars ............... & 24 & 2 & 1 & - & - \\
\hline Avril $\quad \ldots \ldots \ldots \ldots \ldots$ & 17 & - & - & - & - \\
\hline Mai ............... & 15 & 1 & 2 & 1 & - \\
\hline Juin $\ldots \ldots \ldots \ldots \ldots$ & 9 & 1 & 1 & 1 & 1 \\
\hline Juillet $\ldots \ldots \ldots \ldots \ldots$ & 8 & - & - & 2 & 一 \\
\hline Août $\ldots \ldots \ldots \ldots \ldots$ & 8 & 1 & 1 & 1 & 2 \\
\hline Septembre .......... & 14 & 1 & 1 & 1 & - \\
\hline Oetobre ............ & 12 & - & - & 1 & - \\
\hline Novembre ............ & 11 & 1 & - & - & - \\
\hline Décembre........... & 4 & - & - & - & - \\
\hline Total..... & 151 & 11 & 9 & 8 & 3 \\
\hline
\end{tabular}

Egalement pour le babeurre, le titrage du Bacterium Coli parut être une méthode d'analyse convenable.

Généralement, on admet que dans le babeurre ne se trouvent pas ou se ne se trouvent qu'exceptionnellement des organismes Coli; les bactéries lactiques (ou l'acide lactique) les détruiraient. Cependant, chaque été, le Service d'Inspection reçut des plaintes de légères intoxications à la suite de la consommation de babeurre ; lors d'examen du babeurre, on ne trouva jamais des bactéries d'affections spécifiques, mais toujours des colibacilles. Alors, nous nous sommes demandé si l'affirmation, que dans le babeurre, on ne trouve en règle générale pas d'organismes Coli, est bien justifiée, et, pour résoudre la question, nous avons d'abord examiné si la méthode de titrage du Bacterium Coli qui a été déterminée pour le lait, peut être utilisée pour le babeurre. La méthode parut convenable ; une modification dut être apportée : au mélange de $1 \mathrm{~cm}^{3}$ de babeurre et de $9 \mathrm{~cm}^{3}$ de solution de peptone (première dilution), on ajoute un peu de carbonate de calcium.

L'examen démontra que dans $70 \%$ des échantillons de babeurre se trouvent des organismes Coli, et dans beaucoup d'entre eux même, en très grand nombre; d'où il résulte qu'il faut déterminer le titre 
de Bacterium Coli jusqu'à la dilution $1: 10.000 .000 .000$ (titre 10). Au cours du deuxième semestre de l'année 1933, il fut examiné 489 échantillons de babeurre, avec les résultats suivants :

TITRAGE DU "B IGTERIUM COLI "ÉCHANTILLONS DE BABEURRE, AU COURS DU DEUXIÈME SEMESTRE DE L'ANNÉE 1933.

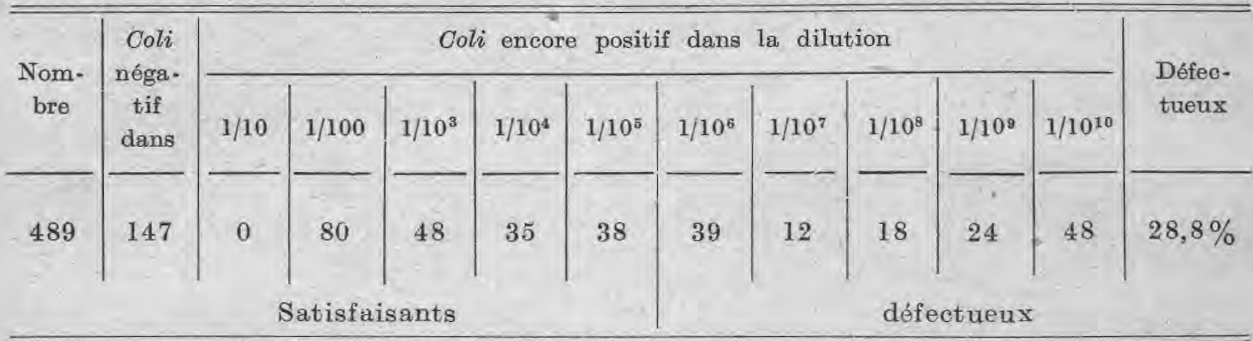

Nous basant sur ces résultats, nous sommes d'avis que nous devons considérer comme insuffisamment purs les échantillons dont le taux en Bacterium Coli est égal à 6 ou plus élevé, c'est-à-dire les échantillons qui permettent, par une dilution égale ou supérieure à 1 : 1.000 .000 , de trouver encore des organismes Coli.

Cette eonclusion ne peut être justifiée que lorsque les résultats obtenus ne sont pas complètement dus au hasard, mais lorsqu'il est possible d'indiquer une cause pour ces titres élevés. Nous sommes d'avis que nous pouvons considérer comme cause de ces titres de Bacterium Coli trop élevés : la préparation du babeurre de lait retourné (1), qui n'a pas été l'objet de soins suffisants, c'est-à-dire du lait retourné conservé à une température trop élevée ou qui a été conservé trop longtemps.

Le fait que le hasard ne peut être accusé, nous fut facilement démontré par cette constatation : le babeurre de certaines exploitations ne présente jamais un taux élevé de Bacterium Coli. Les laiteries où le lait retourné est pasteurisé avant le barattage, fournissent presque toujours du babeurre pauvre en Bacterium Coli, comme le démontre le tableau suivant :

TITRAGE DU “ BACTERIUM COLI " D'ÉCHANTILLONS DE BABEURRE AU GOURS DE L'ANNÉE 1933.

Nombre Dont titre :

d'échan- nég. $2 \quad 3 \quad 4 \quad 5$

tillons satisfaisant

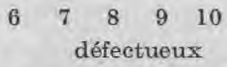

Laiterie A .......

11

Laiterie B .......

14

$\begin{array}{lllll}0 & 2 & 2 & 2 & 3\end{array}$

$\begin{array}{lllll}0 & 4 & 6 & 1 & 2\end{array}$

$\begin{array}{lllll}5 & 7 & 4 & 2 & 1\end{array}$ $\begin{array}{lllll}1 & 0 & 1 & 0 & 0\end{array}$

$1 \quad 000000$

$\begin{array}{lllll}1 & 1 & 2 & 1 & 1\end{array}$

Deux autres exploitations fournirent :
Laiterie D .......
5
$\begin{array}{lllll}0 & 0 & 0 & 0 & 1\end{array}$
Laiterie E. . . . . . .
8
$\begin{array}{lllll}0 & 0 & 0 & 1 & 1\end{array}$
$\begin{array}{lllll}2 & 1 & 1 & 0 & 0\end{array}$
$\begin{array}{lllll}0 & 0 & 2 & 2 & 2\end{array}$

(1) Lait retourné, lait qui n'a pas été vendu et est revenu à la laiterie. 
Des fermes-modèles fournirent les résultats suivants :

$\begin{array}{lllllllllllll}\text { Etable-modèle F . } & 14 & 0 & 0 & 3 & 3 & 4 \\ \text { Etable-modèle G . } & 24 & 0 & 0 & 1 & 0 & 1\end{array}, \begin{array}{lllll}1 & 1 & 1 & 0 & 1 \\ 1 & 1 & 3 & 8 & 9\end{array}$

Il est done certain que l'exploitation $\mathrm{F}$ apporte beaucoup plus de soins à la préparation du babeurre que l'exploitation G.

Il nous parait done établi, que lorsqu'on apporte suffisamment de soins à la préparation du babeurre, son titre en Bacterium Coli ne doit pas être plus élevé que 5 . Il a déjà été démontré que l'augmentation de soins a pour résultat une baisse du titre de Bacterium Coli.

Sur notre demande, M. RAAFF, ingénieur chimiste des étables "Oud Bussem ", a examiné les modifications du titre de Bacterium Coli du babeurre au cours de la conservation. Il fut démontré qu'il subit une légère baisse au cours de 24 heures, surtout lorsque, lors du premier examen, la teneur du babeurre en organismes Coli était très élevée. Ce résultat ne constitue pas un argument contre l'utilisation de la méthode pour l'examen pratique du babeurre, parce que du babeurre aussi vieux, est déjà impropre à la consommation, par suite d'autres défauts (fermentation).

Provisoirement, nous maintenons notre avis, que les plaintes au sujet de troubles intestinaux subis à la suite de la consommation de babeurre, dont quelques-unes nous parviennent chaque été, sont attribuables à une teneur élevée du babeurre en Bacterium Coli. Il faut cependant admettre que d'autres facteurs interviennent encore; sans cela, les plaintes seraient plus nombreuses, étant donné les grandes quantités de babeurre défectueux au point de vue bactériologique, qui sont encore mises en vente.

Il arrive parfois que certaines espèces de fromages donnent lieu à des symptômes de maladie analogues à ceux de maladie constatée après la consommation de babeurre. Lorsqu'on détermine alors le titre de Bacterium Coli d'un tel fromage, il est toujours élevé (présence d'indol dans $1 / 1.000^{\circ}$ ou $1 / 10.000^{\circ}$ de gramme de fromage), tandis que, dans du fromage sain de lá même espèce, on ne parvient pas à déterminer la présence du Bacterium Coli.

En résumé, je pense être autorisé à préconiser le titrage de l'indol pour l'examen du fromage, du babeurre, du lait pasteurisé et surtout du lait cru. La recherche de l'indol fournit une indication nette, facile à obtenir, sur la qualité hygiénique de ces produits, même dans les cas où le titrage de l'acidité et la réductase fournissent encore des résultats favorables.

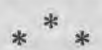

Ce m'est un agréable devoir de remercier le $\mathrm{D}^{\mathrm{r}} \mathrm{A}$. Van RaAlte et l'Ingénieur J. Strad b de l'intérêt qu'ils m'ont témoigné et de leur aide au cours des recherches qui sont décrites dans ce mémoire.

(Traduction de R. N. Göransson.) 